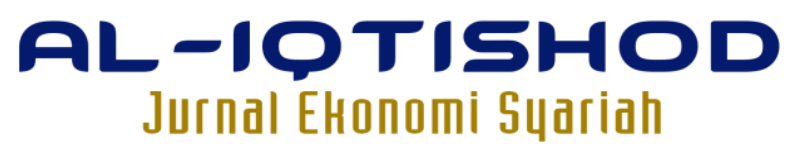

INSTITUT AGAMA ISLAM SUNAN KALIJOGO MALANG

P-ISSN 2715-7725 / E-ISSN 2721-9496

Volume 2, Nomor 2 / Desember 2020

\title{
IMPLEMENTASI ETIKA BISNIS ISLAM: BISNIS HALAL YANG BERTANGGUNG JAWAB
}

\author{
Priatmojo Suryo Kuncoro'), Siti Nurul Amaliyah ${ }^{2)}$ \\ 1), 2)Institut Agama Islam Sunankalijogo Malang \\ 1uncoro.iaiskj@gmail.com
}

\begin{abstract}
Abstrak: Manusia memiliki kebutuhan hidup yang mengharuskan untuk memiliki materi yang cukup dalam pemenuhan kebutuhan tersebut. Untuk mendapatkan materi maka manusia harus bekerja, baik secara formal maupun informal. Bekerja secara informal salah satunya dapat dilakukan dengan berbisnis. Dimana kehidupan sehari-hari manusia sangatlah berdekatan dengan kata bisnis. Bisnis adalah kegiatan yang menghasilkan barang dan jasa untuk memenuhi kebutuhan hidup masyarakat.

Fakta kegagalan yang paling terasa dari modernisasi yang merupakan akibat langsung dari era globalisasi adalah dalam bidang ekonomi dengan kenyataannya yang justru melahirkan berbagai persoalan, terutama bagi negara-negara Dunia Ketiga (termasuk negara-negara Muslim) yang cenderung menjadi obyek daripada menjadi subyek kapitalisme. Situasi ketidakadilan ekonomi menjadi masalah yang cukup serius, sehingga aspek etika bisnis tidak dapat dipahami semata-mata hanya sebagai usaha intelektual manusia untuk menalarkan moral.

Sebab betapapun peredaran perekonomian berjalan lancar dengan laju ekonomi yang tinggi dan tingkat inflasi yang rendah, namun jika tidak diimbangi dengan etika moral atau nilai-nilai luhur, maka pada titik tertentu akan tercipta kondisi yang membawa malapetaka baik langsung ataupun jangka panjang. Karena itu, Islam menekankan agar aktifitas bisnis manusia dimaksudkan tidak semata-mata sebagai alat pemuas keinginan (al-syahwat), tetapi lebih pada upaya pencarian kehidupan berkeseimbangan dunia-akhirat disertai prilaku positif bukan destruktif.
\end{abstract}

\section{Kata kunci: modernisasi, etika bisnis, keseimbangan dunia akhirat}

\begin{abstract}
Humans have the necessities of life which require that they have sufficient material to fulfill these needs. To obtain material, humans must work, both formally and informally. One way of working informally can be done by doing business. Where the daily life of humans is very close to the word business. Business is an activity that produces goods and services to meet the needs of society. The fact that the most felt failure of modernization, which is a direct result of the era of globalization, is in the economic field, in fact that has created various problems, especially for Third World countries (including Muslim countries) which tend to be objects rather than subjects of capitalism. The situation of economic injustice is a serious
\end{abstract}




\section{AL-IOTISHOD \\ Jurnal Ehonomi Suariah \\ INSTITUT AGAMA ISLAM SUNAN KALIJOGO MALANG \\ P-ISSN 2715-7725 / E-ISSN 2721-9496 \\ Volume 2, Nomor 2 / Desember 2020}

problem, so that aspects of business ethics cannot be understood as merely an intellectual human effort to reason morally.

This is because no matter how well the economic circulation runs smoothly with a high economic rate and a low inflation rate, if it is not balanced with moral ethics or noble values, then at a certain point there will be conditions that will bring disastrous either immediate or long-term disasters. Therefore, Islam emphasizes that human business activities are intended not merely as a means of satisfying desires (al-syahwat), but rather as an effort to seek a balanced life in the world-hereafter accompanied by positive, not destructive behavior.

Keywords: modernization, business ethics, balance in the hereafter

\section{A. PENDAHULUAN}

\section{Latar Belakang}

Dan dampak dari kemajuan dalam bidang sains dan teknologi, telah menghadapkan manusia pada tantangan yang serius terkait aplikasi aktivitas ekonomi dalam memenuhi kebutuhannya, yang tidak dapat terselesaikan tanpa sistem etika yang efektif. Sejak berabad-abad sebelumnya aktivitas intelektual manusia, etika dan moralitas telah menjadi aspek yang diperdebatkan oleh para filusuf dalam pengembangan penilaian etis. Terutama dalam tataran bisnis, tidaklah cukup hanya bersandar pada etika dan nilai-nilai normatif saja namun perlu diterapkan dan dikembangkan juga secara praktis dalam praktik nyata. ${ }^{1}$

Hukum ekonomi klasik menjelaskan bahwa bisnis dapat dilakukan dengan menggunakan berbagai cara untuk mendapatkan keuntungan, semua cara yang dilakukan dianggap halal, bahkan bangsa Barat menetapkan bahwa manusia sebagai homo ecominicus atau manusia adalah manusia yang mengejar materi saja. Berpedoman pada prinsip bahwa dengan menggunakan modal sekecil mungkin untuk mendapatkan hasil yang berlipat dari modal awalnya, mendukung para pelaku bisnis dalam menjalankan bisnisnya tanpa memikirkan tanggungjawab yang harus dia lakukan. Hal inilah yang memunculkan pemikiran

\footnotetext{
${ }^{1}$ Muatasim Ismaeel, dkk, Toward applied Islamic Business Ethics: Resposible Halal Business
} (Emerald Journal of Management Development: Vol. 31, No. 10, 2012), 1090. 


\section{AL-IOTISHOD \\ Jurnal Ehonomi Suariah \\ INSTITUT AGAMA ISLAM SUNAN KALIJOGO MALANG \\ P-ISSN 2715-7725 / E-ISSN 2721-9496 \\ Volume 2, Nomor 2 / Desember 2020}

bahwa bisnis adalah perkerjaan yang tidak bermoral. Untuk menjadikan bisnis menjadi kegiatan usaha yang baik maka aturan-aturan bisnis harus di lakukan agar bisnis bisa berjalan dengan baik dan tidak merugikan orang lain. ${ }^{2}$

Fakta kegagalan yang paling terasa dari modernisasi yang merupakan akibat langsung dari era globalisasi adalah dalam bidang ekonomi dengan kenyataannya yang justru melahirkan berbagai persoalan, terutama bagi negaranegara Dunia Ketiga (termasuk negara-negara Muslim) yang cenderung menjadi obyek daripada menjadi subyek kapitalisme.3Situasi ketidakadilan ekonomi menjadi masalah yang cukup serius, sehingga aspek etika bisnis tidak dapat dipahami semata-mata hanya sebagai usaha intelektual manusia untuk menalarkan moral.

Pada mulanya etika bisnis muncul ketika kegiatan bisnis tidak luput dari sorotan etika. Menipu dalam bisnis, mengurangi timbangan atau takaran, merupakan contoh- contoh konkrit adanya hubungan antara etika dan bisnis. Dari fenomena-fenomena itulah etika bisnis mendapat perhatian yang intensif hingga menjadi bidang kajian ilmiah yang berdiri sendiri.4 Menurut sementara pihak, problem etika bisnis terletak pada kesangsian apakah moralitas mempunyai tempat dalam kegiatan bisnis. Bagi kalangan ini bisnis adalah kegiatan manusia yang bertujuan mencari laba semata-mata. Bisnis telah ada dalam sistem dan struktur dunianya yang baku untuk mencari pemenuhan hidup. Sementara, etika merupakan disiplin ilmu yang berisi patokan-patokan mengenai apa-apa yang benar atau salah, yang baik atau buruk, sehingga dianggap tidak seiring dengan sistem dan struktur bisnis. Kesangsian-kesangsian inilah yang melahirkan mitos bisnis amoral.5

Oleh karena itu yang menjadi tantangan bagi para akademisi dalam kontribusinya terhadap kemajuan teori dan praktik ekonomi terkhusus pada

\footnotetext{
${ }^{2}$ Sholahuddin, Asas-Asas Ekonomi Islam (Jakarta: PT Raja Grafindo Persada, 2007), 11.

${ }^{3}$ Darmawati, Etika Bisnis dalam Perspektif Islam: Eksplorasi Prinsip Etis Al-Qur'an dan Sunnah (Mazahib: Vol. 13, No. 1, 2013), 58.

${ }^{4}$ Darmawati, Etika Bisnis dalam Perspektif Islam, 60

${ }^{5}$ A. Sony Keraf, Etika Bisnis (Jakarta: Kanisius, 1998), 49.
} 


\section{AL-IOTISHOD \\ Jurnal Ehonomi Suariah \\ INSTITUT AGAMA ISLAM SUNAN KALIJOGO MALANG \\ P-ISSN 2715-7725 / E-ISSN 2721-9496 \\ Volume 2, Nomor 2 / Desember 2020}

aspek etika bisnis adalah menguak keefektivitasan institusi dan mekanisme sosial saat ini dalam menerapakan etika bisnis dan bagaimana hal tersebut dapat ditingkatkan dan disesuaikan dengan prinsip syari'ah dengan menggunakan salah satu contoh peraturan dan sertifikasi halal. Untuk menjawab pertanyaan yang selalu muncul saat membahas keterkaitan antara Islam dan bisnis, yang selama ini dianggap bahwa bisnis adalah sesuatu yang terlepas dari agama baik dari prinsip maupun aplikasinya.

\section{Tujuan}

Berdasarkan fakta dan fenomena di masyarakat terkait aplikasi bisnis yang cenderung condong pada unsur monopoli, dzalim, riba dan praktik-praktik yang menghalalkan segala cara. Sedangkan mayoritas penduduk dunia dan penduduk Indonesia khususnya adalah beragama Islam. Sehingga peneliti bertujuan untuk ikut berkontribusi dalam pengembangan dan penerapan etika bisnis Islam melalui mekanisme kontemporer penerapan etika bisnis yang terfokus pada peraturan dan sertifikasi halal sebagai aplikasi etika bisnis Islam, yang dapat dijabarkan sebagai berikut:

1. Untuk memahami tentang konsep etika bisnis Islam

2. Untuk memahami bentuk pengembangan peraturan dan sertifikasi halal sebagai aplikasi etika bisnis Islam

\section{B. KAJIAN LITERATUR}

1. Bisnis

Seorang manusia memiliki kebutuhan yang banyak dalam memenuhi aktivitas-aktivitasnya. Kebutuhan manusia tidak hanya kebutuhan berupa barang saja melainkan kebutuhan akan jasa. Kebutuhan akan barang dan jasa akan terpenuhi saat mereka memiliki kemampuan untuk mencari lalu mengolahnya menjadi yang mereka butuhkan. Namun ada sebagian orang yang tidak dapat membuat dan mengolahnya sendiri, sehingga membutuhkan peran manusia lain (penjual atau penyedia) dalam pemenuhan kebutuhan tersebut. Selain sebagai 


\section{AL-IOTISHOD \\ Jurnal Ehonomi Suariah \\ INSTITUT AGAMA ISLAM SUNAN KALIJOGO MALANG \\ P-ISSN 2715-7725 / E-ISSN 2721-9496 \\ Volume 2, Nomor 2 / Desember 2020}

kegiatan pemenuhan barang dan jasa, kegiatan ini juga dijadikan sebagai cara untuk mendapatkan profit atau laba. Laba yang diperoleh akan digunakan kembali untuk memenuhi kebutuhannya (penjual atau penyedia). Kegiatan dengan keinginan mencari laba inilah disebut dengan bisnis.

Secara historis kata bisnis berasal dari bahasa Inggris yaitu "business", dari kata dasar "busy" yang artinya "sibuk". Sibuk mengerjakan aktivitas dan pekerjaan yang mendatangkan keuntungan. Dalam kamus bahasa Indonesia bisnis adalah usaha dagang; usaha komersial.6 Bisnis sendiri memiliki dua pengertian yang berbeda, yakni : pertama, bisnis adalah sebuah kegiatan. Kedua, bisnis adalah sebuah perusahaan. Bisnis dapat dikatakan sebuah kegiatan yang terorganisir karena didalam bisnis ada banyak kegiatan yang dilakukan. Kegiatan dimulai dengan input berupa mengelola barang lalu diproses setelah itu menghasilkan output berupa barang setengah jadi atau barang jadi. Sedangkan secara etimologi, bisnis memiliki arti dimana seseorang atau sekelompok dalam keadaan yang sibuk dan menghasilkan keuntungan atau profit bagi dirinya atau kelompok.7

Kata bisnis dalam Al-Qur'an biasanya digunakan dengan istilah al-tijarah, al-bai', tadayantum, dan isytara. Tetapi yang seringkali digunakan yaitu al-tijarah yang bermakna berdagang atau berniaga. Menurut ar-Raghib al-Asfahani dalam al-mufradat fi gharib al-Qur'an yang dikutip oleh Darmawati bahwa at-tijarah bermakna pengelolaan harta benda untuk mencari keuntungan. Dalam penggunaan kata tijarah pada ayat-ayat Al-qur'an terdapat dua macam pemahaman, yaitu: Pertama, dipahami dengan makna perdagangan yaitu pada surat Al-Baqarah: 282. Kedua, dipahami dengan perniagaan dalam pengertian umum. 8

208

${ }^{6}$ Tim Redaksi Kamus Bahasa Indonesia, Kamus Bahasa Indonesia (Jakarta:Pusat Bahasa, 2008),

${ }^{7}$ Wikipedia, "Bisnis", http://id.wikipedia.org/wiki/Bisnis

${ }^{8}$ Darmawati, Etika Bisnis dalam Perspektif Islam, 61. 


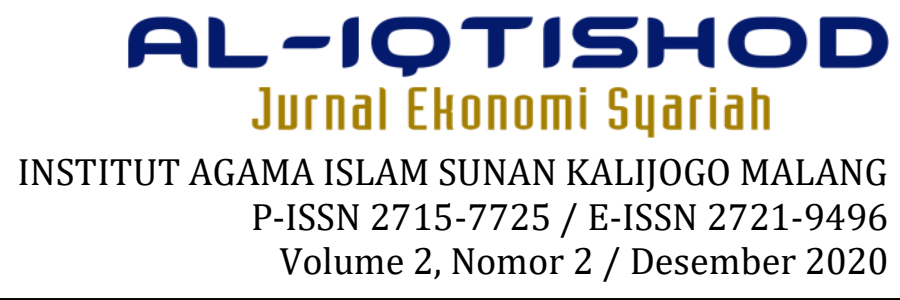

Dari penjelasan di atas, terlihat bahwa term bisnis dalam Al-Qur'an dari tijarah pada hakikatnya tidak semata-mata bersifat material dan hanya bertujuan mencari keuntungan material semata, tetapi bersifat material sekaligus immaterial, bahkan lebih meliputi dan mengutamakan hal yang bersifat immaterial dan kualitas. Aktivitas bisnis tidak hanya dilakukan manusia semata tetapi juga dilakukan antara manusia dengan Allah SWT, bahwa bisnis harus dilakukan dengan ketelitian dan kecermatan dalam proses administrasi dan akad serta tidak boleh adanya unsur penipuan, kecurangan hanya karena untuk mendapat keuntungan.9 Dalam hal ini, ada dua definisi tentang pengertian bisnis, dari dua sudut pandang yang berbeda, yaitu menurut mufassir dan ilmu fikih:10

1) Menurut Mufassir, Bisnis adalah pengelolaan modal untuk mendapatkan keuntungan

2) Menurut Tinjauan Ahli Fikih, Bisnis adalah saling menukarkan harta dengan harta secara suka sama suka, atau pemindahan hak milik dengan adanya penggantian.

\section{Etika Bisnis Islam}

Secara etimologi bahasa etika (ethics) yang berasal dari bahasa Yunani (ethikos) mempunyai beragam arti : pertama, sebagai analisis konsep-konsep terhadap apa yang harus, mesti, tugas, aturan-aturan moral, benar, salah, wajib, tanggung jawab dan lain-lain. Kedua, aplikasi ke dalam watak moralitas atau tindakan-tindakan moral. Ketiga, aktualisasi kehidupan yang baik secara moral. Etika merupakan filsafat tentang moral. Jadi sasaran etika adalah moralitas.11Menurut David P. Baron, etika adalah suatu endekatan yang sistematis atas penilaian moral yang didasarkan pada penalaran, analisis, sistesis,

${ }^{9}$ Muhammad Luqman Fauroni R, Visi Al-Qur'an Tentang Etika dan Bisnis (Jakarta: Salemba Diniyyah, 2002), 70.

${ }^{10}$ Ahmad Wardi Muslich, Fiqh Muamalat (Jakarta: Amzah, 2010), 13.

${ }^{11}$ Darmawati, Etika Bisnis dalam Perspektif Islam, 60. 


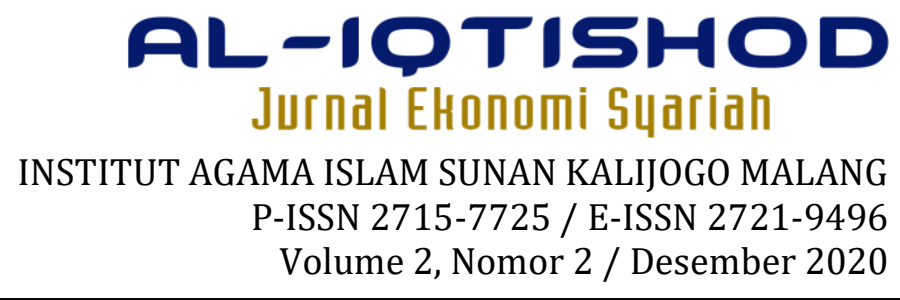

dan reflektif. Sedangkan menurut Lawrence, Weber dan Post berpendapat bahwa setika adalah suatu onsepsi tentan tingkah laku yang benar dan salah.12

Dalam ajaran Islam, istilah yang paling dekat berhubungan dengan istilah etika dalam Al-Quran adalah Khuluq. Pandangan Al-Asfahani dalam mengartikan Khuluq yang dikutib oleh Darmawati, pada firman Allah انك لعلي خلق عظيم dengan : ما اكتسب الانسان من الفضيلة بخلقه $\quad$ yang artinya: apa yang diusahakan manusia untuk mencapai kemuliaan sesuai dengan penciptaannya. Dimana dalam khazanah pemikiran Islam, etika dipahami sebagai Al-Akhlaq atau Al-Adab yang bertujuan untuk mendidik moralitas manusia. Etika terdapat dalam materi-materi kandungan ayat-ayat Al-Quran yang sangat luas, dan dikembangkan dalam pengaruh filsafat Yunani hingga para sufi. ${ }^{13}$

Seperti yang telah difirmankan Allah dalam Al-qur'an (QS: Al-Baqarah ayat 30) yang menyatakan bahwa manusia adalah wakil Allah di bumi. Sehingga menurut terjemahan Yosuf Ali yang disimpulkan oleh Muatasim bahwa konsep Khilafa (wakil) adalah dasar keberadaan manusia dan mengharuskan manusia untuk memiliki komitmen etis sesuai ajaran Islam atas misi mereka di bumi. Dimana misi tersebut dipahami sebagai bentuk pemujaan kepada Allah melalui pembangunan dan pemeliharaan kehidupan yang adil dan makmur di bumi. ${ }^{14}$

Ajaran Islam yang biasa disebut syariah telah menggambarkan bentuk hukum Islam yang berisi seperangkat norma, nilai dan hukum untuk membentuk jalan hidup Islam. Norma dan nilai komponen syariah inilah yang dapat digunakan untuk meningkatkan etika bisnis dalam praktik bisnis Muslim yang tidak lain untuk memenuhi kewajiban mereka sebagai wakil Allah di bumi. ${ }^{15}$ Sebab tanpa adanya etika atau akhlak dalam bisnis, manusia akan

${ }^{12}$ Sukrisno Agoes, dkk, Etika Bisnis dan Profesi Tantangan Membangun Manusia Seutuhnya (Jakarta: Salemba Empat, 2014), 27.

${ }^{13}$ Darmawati, Etika Bisnis dalam Perspektif Islam, 61.

${ }^{14}$ Muatasim Ismaeel, dkk, Toward applied Islamic Business Ethics, 1090

${ }^{15}$ Muatasim Ismaeel, dkk, Toward applied Islamic Business Ethics, 1091 


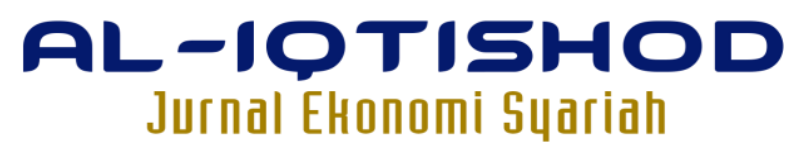

INSTITUT AGAMA ISLAM SUNAN KALIJOGO MALANG

P-ISSN 2715-7725 / E-ISSN 2721-9496

Volume 2, Nomor 2 / Desember 2020

semenamena dalam menjalankan bisnis tanpa melihat halal dan haram. Berikut adalah etika bisnis menurut Qardhawi yang dikutip oleh Sentot dalam bukunya Bisnis Modern. ${ }^{16}$

\section{Etika Bisnis Qardhawi}

\begin{tabular}{|l|l|}
\hline \multicolumn{1}{|c|}{ Bidang } & \multicolumn{1}{c|}{ Etika } \\
\hline Produksi & 1. Bekerja adalah hal utama dalam produksi \\
& 2. Produksi yang halal \\
& 3. Perlindungan terhadap kekayaan alam \\
& 4. Mewujudkan swadaya \\
& 5. Merealisasikan swasembada \\
\hline Konsumsi & 1. Menafkahkan harta dalam kebaikan \\
& 2. Tidak berfoya-foya \\
& 3. sederhana \\
\hline Keuangan & 1. Pengakuan hak pribadi \\
& 2. Pengakuan warisan \\
& 3. Kebutuhan Al-qur'an dan neraca \\
& 4. Imbang dalam rizki dan kerja \\
& 5. Memenuhi hak para pekerja \\
\hline Ditribusi & 1. Tidak berdagang barang haram \\
& 2. Sidiq, amanah, jujur \\
& 3. Adil dan menjahui riba \\
& 4. Kasih saying dan tidak monopoli \\
& 5. Toleransi, persaudaraan dan sedekah \\
\hline
\end{tabular}

Etika bisnis Islam ini bertujuan agar setiap kegiatan ekonomi yang dijalankan dapat menyelamatkan sumber daya alam dari penggunaan yang dieksploitasi.

3. Halal

Kata halal yang diserap dari bahasa Arab telah menjadi sangat familier di kalangan masyarakat kita. Namun belum semua kalangan masyarakat mampu memahami makna halal secara tepat. Menurut Mahmud Ismail Sinni

\footnotetext{
${ }^{16}$ Sentot Imam Wahjono, Bisnis Modern (Yogyakarta: Graha Ilmu, 2010), 18.
} 


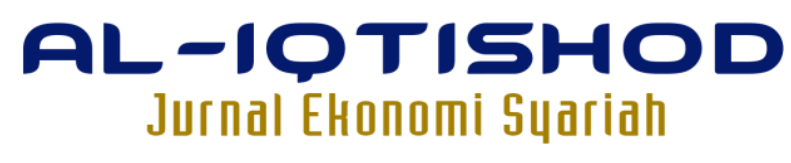

INSTITUT AGAMA ISLAM SUNAN KALIJOGO MALANG

P-ISSN 2715-7725 / E-ISSN 2721-9496

Volume 2, Nomor 2 / Desember 2020

dan Haimur Hasan Yusuf dalam mu'jam al Thullab mengartikan makna halal sebagai sinonim kata jaza' yang berarti boleh atau mubah.17

Dan secara pragmatis konsepsi halal-haram memiliki makan penting dalam perbisnisan, yang lahir bukan hanya dari produk manusia melainkan sebuah ketentuan dari Allah. Sedangkan dalam praktik-praktik bisnis di lapangan menunjukkan adanya transformasi niai kea rah yang bersifat multi makna. Bagi produsen secara sederhana halal dimaknai bahwa produk yang dihasilkan tidak mengandung bahan-bahan yang haram. Padahal jika ditelaah lebih dalam, konsepsi hala-haram dalam perspektif syari'ah juga harus menunjukkan keloyalannya pada dimensi sosial. 18 Adapun menurut Muhammad konsepsi halal harus mencakup:19

a. Halal: Bebas dari kontaminasi barang-barang haram seperti daging babi dan alkohol

b. Halal: Pembebasan konsumen dari keraguan

c. Halal: Produk bersih dan suci, dimana bersih dimaknai terbebas dari unsur-unsur yang mengandung najis dan suci berarti terbebas dari kontaminasi barang-barang haram

d. Halal: Tanggung jawab sosial industry terhadap lingkungan

e. Halal: Makna informatif yang merujuk pada segmen konsumen tertentu untuk menepis keraguan terhadap produk yang dihasilkan.

\section{METODOLOGI PENELITIAN}

Peneliti akan menggunakan metodologi pendekatan ekonomi Islam yang dipadukan dengan aspek normative pada pendekatan fiqih, ushul fiqih dan tafsir dalam sebuah kajian epistemologi dan fenomenologi untuk mengungkap dan menjawab permasalahan serta menawarkan sebuah konsep

\footnotetext{
${ }^{17}$ Muhammad, dkk, Label Halal antara Spiritualisme Bisnis dan Komoditas Agama (Malang: Madani, 2009), 9.

${ }^{18}$ Muhammad, dkk, Label Halal..., 32.

${ }^{19}$ Muhammad, dkk, Label Halal..., 32-49. 


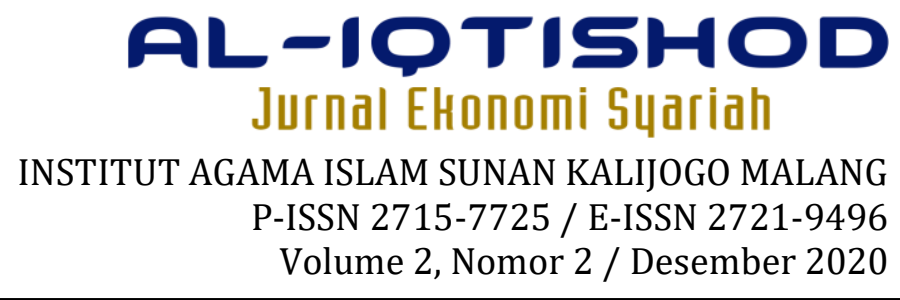

aplikasi etika bisnis Islam yang berfokus pada peraturan dan sertifikasi halal sebagai penerapan etika bisnis Islam.

Peneliti menggunakan jenis penelitian literature atau (library research) yang dilakukan dalam bentuk penelitian kualitatif deskriptif yang nantinya akan menghasilkan gambaran obyek. Dimana sumber data penelitian didapatkan dari observasi dan dokumentasi yang dilakukan dengan cara pengumpulan beberapa informasi dari buku-buku, jurnal, karya ilmiah dan website yang berkaitan dengan penelitian.

\section{PEMBAHASAN}

\section{Penerapan etika bisnis Islam}

Dewasa ini globalisai ekonomi memiliki andil besar dalam proses transformasi budaya konsumtif dan gaya hidup masyarakat. Konsumsi, yang dulunya merupakan sebuah kebutuhan biologis semata kini telah bertranformasi, bukan saja pada pemenuhan kebutuhan makan melainkan sudah menjadi gaya hidup (life style) dan bahkan sudah dijadikan simbolisasi dari status sosial seseorang. Globalisasi secara kongkrit telah menciptakan kelimpah-ruahan material yang mendorong masyarakat berbudaya konsumtif. ${ }^{20}$ Serta menempatkan bisnis dan nilai etika maupun moralitas agama sebagai dua kutub yang binary opposition tidak lain adalah cara pandang sistem kapitalisme, yang memandang tujuan akhir dari sebuah bisnis sebagai sarana akumulasi modal (capital accumulation) dan maksimalisasi laba (pro fit maximizing) dalam bentuk kekayaan (uang atau material). ${ }^{21}$

Islam bukan hanya sebuah agama yang dianut oleh manusia, tetapi Islam juga merupakan pedoman hidup bagi para penganutnya, di mana setiap aspek dalam kehidupan manusia telah diatur menurut hukum Islam. Salah satunya adalah aspek dalam etika bisnis Islam yang tidak bisa dipisahkan

\footnotetext{
${ }^{20}$ Muhammad, Label Halal dan Spiritualitass Bisnis (E-Journal UMM: Vol. 12, No. 2, JuliDesember 2009), 101.

${ }^{21}$ Muhammad, Label Halal dan Spiritualitass Bisnis, 102
} 


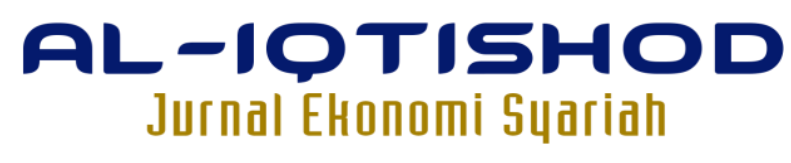

INSTITUT AGAMA ISLAM SUNAN KALIJOGO MALANG

P-ISSN 2715-7725 / E-ISSN 2721-9496

Volume 2, Nomor 2 / Desember 2020

dengan hal-hal penting lainnya. Dimana inti dari etika bisnis Islam adalah konsep Tauhid. Namun syariat Islam yang telah mengatur cara pemenuhan kebutuhan manusia sesuai dengan tuntutan garis-garis maqashid asy syariah serta konsep-konsep dalam pengaturan bisnis selama ini masih tersimpan rapi dalam literatur-literatur fiqh klasik yang kurang elaborate bahkan dipandang sebelah mata dalam tatanan ekonomi dan bisnis. ${ }^{22}$

Dan yang menjadi tantangan utama bagi sistem etika adalah bentuk penerapan dan aplikasinya. Dahulu orang-orang muslim telah berhasil menerapkan sistem etika melalui mekanisme yang efektif dengan adanya institusi hisbah sebagai otoritas standar perdagangan. Namun lingkungan bisnis telah bertransformasi dari mekanisme tradisional menjadi mekanisme kontemporer. Banyak peneliti yang telah berkontribusi pada teori-teori normatif yang menjelaskan tentang sistem nilai dan pedoman etika Islam untuk membentuk sistem etika yang kuat dan efektif. Sayangnya ketika melihat kenyataan di negara-negara mayoritas Muslim, ditemukan perbedaan yang jelas antara etika bisnis Islam normatif dan praktik kaum Muslim. ${ }^{23}$

Ada beberapa konsep yang berpotensi diterapkan dalam etika bisnis, salah satunya adalah konsep "filter moral" yang bekerja pada mekanisme harga untuk mengatur pasar. Namun ranah aplikasinya belum dapat direalisasikan dengan baik. Dimana menurut Muatasim ketidak efektifan norma dan etika di sini disebabkan karena tidak adanya kesinkronan dengan definisi praktis, mekanisme dan alat yang dirancang untuk menerapkannya dalam konteks kontemporer. Dan perbedaan antara etika normatif dan praktik dalam masyarakat Muslim dapat dikaitkan dengan kurangnya institusi yang berkembang dengan baik dan efektif yang dapat menerjemahkan konsep normatif ke dalam praktik. ${ }^{24}$

\footnotetext{
${ }^{22}$ Darmawati, Etika Bisnis dalam Perspektif Islam, 60.

${ }^{23}$ Muatasim Ismaeel, dkk, Toward applied Islamic Business Ethics, 1092

${ }^{24}$ Muatasim Ismaeel, dkk, Toward applied Islamic Business Ethics, 1092-1093.
} 


\section{AL-IOTISHOD \\ Jurnal Ehonomi Suariah \\ INSTITUT AGAMA ISLAM SUNAN KALIJOGO MALANG \\ P-ISSN 2715-7725 / E-ISSN 2721-9496 \\ Volume 2, Nomor 2 / Desember 2020}

\section{Kerangka etika Islam multi level}

Fakta bahwa umat Islam mampu membangun peradaban dan kontrol yang kuat dalam perdagangan internasional selama berabad-abad mendukung gagasan bahwa Islam tidak menerapkan pandangan idealis tentang kehidupan dan etika, namun sebaliknya umat Islam berhasil karena ruang fleksibilitas dan kemampuan beradaptasi dalam etika Islam. Fleksibilitas dan kemampuan beradaptasi dari etika Islam adalah bagian dari dinamika syariah yang didukung oleh salah satu konsep dasar dalam teologi Islam yaitu tingkatan agama (Deen). Dimana dalam hadist yan dikenal dengan hadits Jibril dijelaskan bahwa tingkatan agama ada tiga, yakni: (1) Islam, yang berkaitan dengan menaati instruksi dan ajaran Allah; (2) Iman, yang memperhatikan penguatan kepercayaan dan nilai di dalam hati seseorang; (3) Ihsan, dengan menjalani pengalaman spiritual yang selalu ada dalam setiap tindakan. ${ }^{25}$ yang dapat dipahami bahwa tingkat kesadaran etis dan komitmen orang-orang Muslim berbeda sesuai dengan kekayaan dan kedalaman pengalaman religius mereka (tingkat agama).

Selain itu dukungan lain yang digunakan dalam pendekatan multi level ini adalah teori normative etika. (Jonsson, 2011) menyatakan bahwa teori normatif etika secara tradisional dikelompokkan menjadi tiga kategori utama, yaitu: (1) Etika deontologis, menganggap bahwa penilaian etis adalah konstan untuk tindakan apapun karena berasal dari sifat intrinsiknya; (2) etika konsekuensialis, penilaian atas kebenaran bergantung pada konsekuensinya daripada sifat intrinsiknya; (3) etika kebajikan, bersifat holistic yang tidak menilai tindakan sebagai sesuatu benar atau salah, melainkan memandang etika sebagai pengalaman hidup bagi mereka yang memiliki kepribadian etis. Sedangkan etika Islam merupakan sintesa dari ketiga teori normative tersebut manurut (Abdallah, 2010)

${ }^{25}$ Muatasim Ismaeel, dkk, Toward applied Islamic Business Ethics, 1093. 


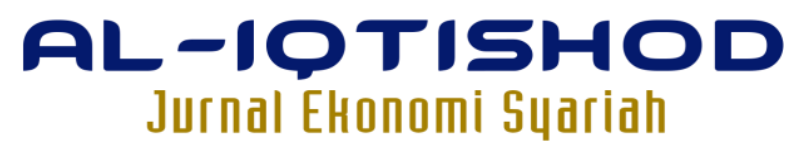

INSTITUT AGAMA ISLAM SUNAN KALIJOGO MALANG

P-ISSN 2715-7725 / E-ISSN 2721-9496

Volume 2, Nomor 2 / Desember 2020

\section{Peraturan dan sertifikasi halal}

Seiring berkembangnya zaman, ilmu pengetahuan dan teknologi semakin berkembang termasuk cara pengolahan barang dan jasa dalam pemenuhan kebutuhan manusia semakin variatif. Dan produk halal menjadi salah satu faktor penting dalam keputusan konsumsi umat Islam. Oleh karena itu, peraturan dan sertifikasi Halal dikembangkan untuk membantu konsumen mengidentifikasi produk, yang sesuai dengan prinsip-prinsip Islam. ${ }^{26} \mathrm{Di}$ Indonesia, sertifikat halal merupakan fatwa tertulis Majelis Ulama Indonesia (MUI) yang menyatakan kehalalan suatu produk sesuai dengan syariah Islam. Yang tidak lain untuk memberikan kepastian kehalalan suatu produk sehingga dapat menentramkan batin yang mengkonsumsi.

Ada dua urgensi dari sertifikasi halal, yaitu: (1) pada aspek moral, sebagai bentuk pertanggungjawaban produsen kepada konsumen; (2) pada aspekk bisnis, sebagai sarana pemasaran untuk meningkatkan kepercayaan dan kepuasan konsumen. Prinsip sistem jaminan halal pada dasarnya mengacu pada konsep Total Quality Management (TQM) yang menekankan pada pengendalian kualitas pada setiap lini. Sistem jaminan halal ini harus dipadukan dalam keseluruhan manajemen yang berpedoman pada empat konsep dasar, yaitu: komitmen yang kuat untuk memenuhi permintaan dan persyaratan konsumen, meningkatkan mutu produksi dengan harga terjangkau, produksi bebas dari kerja ulang, serta bebas dari penolakan dan penyidikan. ${ }^{27}$

\section{Pengembangan peraturan dan sertifikasi halal}

Tantangan dalam menerapkan etika bisnis Islam di masa globalisasi tidak hanya pada aspek penerapan etika bisnis saja, melainkan juga pada aspek pengakomodasian dari sistem dan praktik etika lain yang hadir di

\footnotetext{
${ }^{26}$ Muatasim Ismaeel, dkk, Toward applied Islamic Business Ethics, 1094.

${ }^{27}$ Ramlan, dkk, Sertifikasi Halal sebagai Penerapan Etika Bisnis Islami dalam Upaya Perlindungan bagi Konsumen Muslim (Ahkam: Vol. XIV, No. 1, Januari 2014), 147.
} 


\section{AL-IOTISHOD \\ Jurnal Ehonomi Suariah \\ INSTITUT AGAMA ISLAM SUNAN KALIJOGO MALANG \\ P-ISSN 2715-7725 / E-ISSN 2721-9496 \\ Volume 2, Nomor 2 / Desember 2020}

kancah universal. Untuk langkah pengembangan pasar Halal yang lebih baik dan lebih cepat, maka perlu adanya kolaborasi yang baik antara para pemangku kepentingan utama. Hingga saat ini, pasar halal hampir tidak menemukan potensi untuk mengintegrasikan konsep CSR dan kewarganegaraan perusahaan. Pada saat ini, perusahaan dan badan sertifikasi masih terfokus pada pemenuhan kebutuhan produk dari produk halal (makanan / keuangan). ${ }^{28}$

Hadirnya konsep halal dalam konteks perilaku konsumsi dan produksi mencerminkan upaya manusia dalam memenuhi kebutuhan dan watak dasarnya sebagai makhluk yang memiliki kepastian ketuhanan. Konsumen akan meningkat kesejahteraannya jika ia mengorientasikan perilaku konsumsinya pada produk-produk pangan yang halal dan bermanfaat dan menghindari mengonsumsi barang yang buruk atau haram. ${ }^{29}$ Meskipun sertifikasi halal di sektor pangan dan keuangan telah berkembang khususnya di negara-negara dengan mayoritas Muslim. Namun celah yang perlu untuk ditutup dan diperbaiki terkait standar umum halal yang digunakan. Sebab selama ini setiap negara memiliki standar yang berbeda yang membingungkan konsumen. Maka untuk proses pengembangan peraturan dan sertifikasi halal diperlukan adanya: ${ }^{30}$

1. Harmonisasi standar dan struktur tata kelola, melalui struktur kelembagaan dan tata kelola global yang kuat dan efektif. Agar peraturan dan sertifikasi halal yang diberlakukan dapat bekerja secara efektif sebagai mekanisme penerapan etika Islam dalam jangka panjang. Dan mengatasi masalah ketidak konsistenan peraturan atau sertifikasi halal, serta mampu menjadi fasilitator dalam perdagangan internasional dan memberikan kejelasan lebih bagi pelanggan.

\footnotetext{
${ }^{28}$ Muatasim Ismaeel, dkk, Toward applied Islamic Business Ethics, 1095.

${ }^{29}$ Muhammad, Label Halal dan Spiritualitass Bisnis, 110.

${ }^{30}$ Muatasim Ismaeel, dkk, Toward applied Islamic Business Ethics, 1095-1098.
} 


\section{AL-IOTISHOD \\ Jurnal Ehonomi Suariah \\ INSTITUT AGAMA ISLAM SUNAN KALIJOGO MALANG \\ P-ISSN 2715-7725 / E-ISSN 2721-9496 \\ Volume 2, Nomor 2 / Desember 2020}

2. Peningkatan praktik etika dan tanggung jawab dalam peraturan dan sertifikasi halal, melalui pengintegrasian atribut produk halal dengan praktik tanggung jawab sosial perusahaan (CSR). Label halal bisa menjadi teladan bagi pengembangan bisnis modern dan berkontribusi pada praktik bisnis yang lebih bertanggung jawab. Dengan penerapan praktik CSR dapat membantu mengintegrasikan lebih banyak kriteria dan selanjutnya mengembangkan bisnis halal yang bertanggung jawab. Sebab CSR adalah sebuah konsep yang sudah berkembang dan establish dengan instrument yang digunakan seperti: sertifikasi, penilaian, audit ekstrenal, pegungkapan dan pelaporan wajib. Maka praktik bisnis halal dapat diuntungkan dengan menggunakan dan mengadaptasi alat yang sudah terbukti baik dari CSR. Sehingga dengan mengintegrasikan produk halal dan CSR, ada potensi untuk membangun brand etis secara keseluruhan, berdasarkan etika bisnis Islam dan ditingkatkan dengan atribut produk seperti organik, kesejahteraan hewan, sehat, ramah lingkungan, kondisi kerja yang adil, dan lain-lain.

Karena pada hakikatnya program CSR sendiri telah sejalan dengan substansi ajaran ihsan yang bersumber dari etika bisnis Islam. Dan hanya korporat yang mempunyai spirit teologislah yang mampu melakukan CSR atas dasar ihsan, karena Tuhan mengajarkan bahwa manusia dalam hidupnya harus mempunyai jiwa sosial (social interest), mengedepankan jiwa kemanusiaan (humanistic), saling menolong dalam hal kebaikan (ta'awun), tulus dalam berbagi (ikhlas), dan nilai-nilai kebajikan lainnya. ${ }^{31}$

3. Peraturan dan sertifikasi halal multi level, berdasarkan kerangka etika Islam multi level yang diusulkan sebelumnya, maka pengembangan regulasi halal lembaga sertifikasi dapat menetapkan standar yang

${ }^{31}$ H. Muhammad Djakfar, Corporate Sosial Respnsibility: Aktualisasi Ajaran Ihsan dalam Bisnis (ULUL ALBAB: Vol. 11, No. 1, 2010), 18. 


\section{AL-IOTISHOD \\ Jurnal Ehonomi Suariah \\ INSTITUT AGAMA ISLAM SUNAN KALIJOGO MALANG \\ P-ISSN 2715-7725 / E-ISSN 2721-9496 \\ Volume 2, Nomor 2 / Desember 2020}

berbeda untuk memenuhi kebutuhan berbagai kelompok umat Islam. Dimana peraturan dan sertifikasi halal dapat menambahkan jenis standar dan sertifikat baru, selain standar dasar wajib, yang selama ini masih berfokus pada atribut etika dan tanggung jawab produk menjadi bisnis halal yang mencakup keseluruhan strategi dan proses manajemen perusahaan. Dan pendekatan sertifikasi halal multi level ini dapat berhasil diaplikasikan di dalam praktik bisnis jika pemangku kepentingan pasar halal mampu mengintregasikan lebih banyak faktor ke dalam kriteria penilaian sertifikasi halal.

\section{E. KESIMPULAN}

Penerapan etika bisnis Islam dalam era globalisasi saat ini menjadi sebuah tantangan besar bagi umat muslim. Peraturan dan sertifikasi halal merupakan mekanisme yang baik untuk membantu umat Islam dalam memenuhi komitmen keagamaannya dalam praktik etika bisnis Islam. Dimana praktik bisnis halal ini bervariasi antara satu negara dengan negara lain, sebab sampai saat ini masi belum ada standar umum penilaian sertifikasi halal secara global.

Namun peraturan dan sertifikasi halal dapat dikembangkan dengan memperbaiki struktur kelembagaan dan tata kelola global terkait peraturan sertifikasi halal, mengintegrasikan beberapa alat yang telah terbukti establish dari CSR dengan memasukkan kriteria etika dan tanggung jawab serta menggunakan pendekatan multi level yang memberi informasi kepada orangorang tentang produk dan bisnis yang mencakup kriteria etika dan tanggung jawab bisnis secara menyeluruh baik dari sisi produk maupun manajemen. Dan untuk penelitian selanjutnya, dapat dilakukan penelitian lebih lanjut secara empiris terkait penerapan etika bisnis Islam dan praktik bisnis halal. 


\section{AL-IOTISHOD \\ Jurnal EHonomi Sцагіah \\ INSTITUT AGAMA ISLAM SUNAN KALIJOGO MALANG \\ P-ISSN 2715-7725 / E-ISSN 2721-9496 \\ Volume 2, Nomor 2 / Desember 2020}

\section{DAFTAR PUSTAKA}

Agoes, Sukrisno; Ardana, I Cenik. 2014. Etika Bisnis dan Profesi Tantangan Membangun Manusia Seutuhnya. Jakarta. Salemba Empat.

Darmawati. 2013. Etika Bisnis dalam Perspektif Islam: Eksplorasi Prinsip Etis Al-Qur'an dan Sunnah. Mazahib. Vol. 13. No. 1, 2013.

Djakfar, Muhammad. 2010. Corporate Sosial Respnsibility: Aktualisasi Ajaran Ihsan dalam Bisnis. ULUL ALBAB. Vol. 11. No. 1, 2010.

Fauroni , Muhammad Luqman. 2002. Visi Al-Qur'an Tentang Etika dan Bisnis. Jakarta. Salemba Diniyyah.

Ismaeel, Muatasim; Blaim, Katharina. 2012. Toward applied Islamic Business Ethics: Resposible Halal Business. Emerald Journal of Management Development. Vol. 31. No. 10, 2012.

Keraf, A. Sony. 1998. Etika Bisnis. Jakarta. Kanisius.

Muhammad. 2009. Label Halal dan Spiritualitass Bisnis. E-Journal UMM. Vol. 12. No. 2, Juli-Desember 2009.

Muhammad; As Pelu, Ibnu Elmi. 2009. Label Halal antara Spiritualisme Bisnis dan Komoditas Agama. Malang. Madani.

Muslich, Ahmad Wardi. 2010. Fiqh Muamalat. Jakarta. Amzah.

Ramlan. 2014. Sertifikasi Halal sebagai Penerapan Etika Bisnis Islami dalam Upaya Perlindungan bagi Konsumen Muslim. Ahkam. Vol. XIV, No. 1, Januari 2014.

Sholahuddin. 2007. Asas-Asas Ekonomi Islam. Jakarta. PT Raja Grafindo Persada.

Tim Redaksi Kamus Bahasa Indonesia. 2008. Kamus Bahasa Indonesia. Jakarta. Pusat Bahasa.

Wahjono, Sentot Imam. 2010. Bisnis Modern. Yogyakarta. Graha Ilmu.

Wikipedia, "Bisnis”, http://id.wikipedia.org/wiki/Bisnis

Zakaria, Aceng. 2012. Etika Bisnis Islam. Jakarta. Penerbit Ibnu Azka. 